\title{
The industry engagement ladder
}

\author{
Dylan Rees \\ Swansea University, Swansea, UK, and \\ Qiru Wang and Robert S. Laramee \\ School of Computer Science, University of Nottingham, Nottingham, UK
}

\begin{abstract}
Purpose - This paper is a response to a frequently asked question from prospective industry partners searching for opportunities to collaborate with the Computer Science Department of Swansea University, UK. This paper seeks to provide structured guidance in the form of what is titled the Industry Engagement Ladder. Design/methodology/approach - The Industry Engagement Ladder presents a selection of collaboration opportunities, outlining the possible cooperation mechanisms between an industry partner and the academic institution.

Findings - Opportunities are described and ranked according to the amount of investment required by the industrial partner, and therefore risk, from low to high.

Originality/value - This concise paper provides a quick reference for perspective industry academia collaboration opportunities, the risks involved with each, the possible funding available to help foster these partnerships and the benefits to industry. These collaborative activities (and variations thereof) can be incorporated by any university department. The manuscript offers an ideal starting point for industryuniversity collaboration.
\end{abstract}

Keywords Engagement, Opportunities, Collaboration, Industry-university

Paper type Viewpoint

\section{Introduction and motivation}

There is a growing body of evidence to suggest that industry-academic collaboration provides benefits for both parties. Shneiderman provides evidence that academic papers coauthored with a corporate partner generate a higher impact (Shneiderman, 2018). Additionally, a systematic review by Perkmann et al. (2013) shows a positive correlation between academic success and academic collaboration. However, there are known gaps between industry and academia (Laramee, 2017). For industry partners, collaboration with academia provides an avenue for knowledge transfer, raising awareness of the state-of-theart technology, providing access to specialists in the field and opportunities to potential hires. Collaboration also offers an opportunity to advertise to talented students and develop a relationship with them for potential employment. Collaboration also mitigates risk of testing new potentially risky ideas and projects.

The contributions of this paper are as follows:

(1) The first paper of its kind to offer a concise overview and practical examples of industry-higher education collaborations.

(2) Explicit recommendations outlining the opportunities for industry collaboration with a computer science department at a British university (e.g. Swansea University).

(3) A ranking of collaboration opportunities by investment and risk, see Figure 1.

(C) Dylan Rees, Qiru Wang and Robert S. Laramee. Published in Journal of Industry-University Collaboration. Published by Emerald Publishing Limited. This article is published under the Creative Commons Attribution (CC BY 4.0) licence. Anyone may reproduce, distribute, translate and create derivative works of this article (for both commercial and non-commercial purposes), subject to full attribution to the original publication and authors. The full terms of this licence may be seen at http:// creativecommons.org/licences/by/4.0/legalcode.

Received 3 February 2020 Revised 4 July 2020 Accepted 31 July 2020 


\section{JIUC 2,3}

\section{6}

Figure 1.

The Industry Engagement Ladder, outlining collaboration opportunities for industry partners looking to collude with academia. The higher up the ladder, the higher the investment and therefore risk. Greater investment usually corresponds to a longer relationship. The level of risk is graded on a scale from 1 - very low to 5 - high. The level of investment is also graded on a scale from 1 to $5 ; 1$ negligible costs, 2 $<£ 5 \mathrm{~K}, 3-<£ 50 \mathrm{~K}, 4-$ $<£ 500 \mathrm{~K}, 5->£ 1 \mathrm{~m}$. The nature of the activity is indicated by a $\mathrm{T}$ for teaching-based collaboration and $\mathrm{R}$ for a research-based collaboration

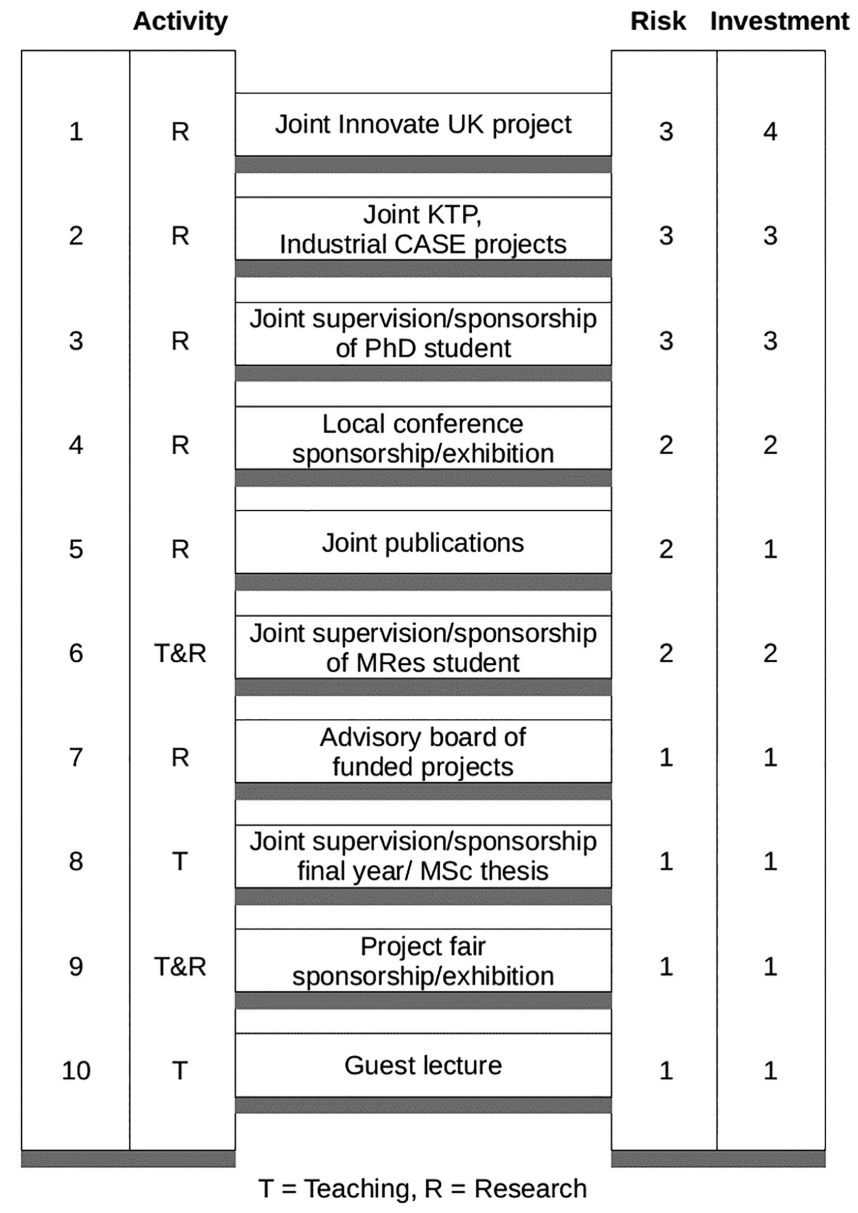

These ideas are generalised and can be applied to any cross-disciplinary configuration. The remainder of this paper begins with related work in Section 2. The Industry Engagement Ladder is presented in Section 3. Section 5 presents a discussion and future work.

\section{Related work}

Industry-university collaboration has long been recognised as a beneficial process and has long been a subject of investigation. As such, many research papers have been published on the subject. We identify six survey papers that address the topic of university-industry collaboration: (Perkmann et al., 2013; Ankrah and Al-Tabbaa, 2015; Garousi et al., 2016; De Wit-de Vries et al., 2018; Mascarenhas et al., 2018) (see Figure 2). Perkmann et al. provide a systematic review of papers published between 1980 and 2011 concerned with academic engagement and compare their results with academic commercialisation and how the two differ (Perkmann et al., 2013). They define academic commercialisation as the creation of intellectual property or the forming of joint enterprises. Specific aspects of collaboration, such as the type and extent of engagement, and the consequences of engagement form the 
categorisation of the findings and discussion. Their findings suggest that academic success and academic engagement are positively correlated.

Ankrah and Al-Tabbaa (2015) provide a systematic review of 109 studies spanning 1990 2014, classified based on five main aspects: types of collaboration, collaboration motivation, collaboration formation and operation, facilitators and inhibitors and outcomes. They present a list of methods for industry-university collaboration as a part of their survey. The list modifies work previously presented by Bonaccorsi and Piccaluga (1994) which presents six categories of collaboration: personal informal relationships, personal formal relationships, third party, formal targeted agreements, formal non-targeted agreements and focussed structures. Ankrah and Al-Tabbaa extend this to include additional forms of collaborations they identify in their survey (Ankrah and Al-Tabbaa, 2015). The list is arranged according to the resource involvement from the university, for example, a low involvement interaction is for an industry partner to deliver a lecture, classified as a personal informal lecture, while a high involvement activity would be funding a university post, classed as a formal nontargeted agreement. Our paper bears resemblance to this work and explicitly outlines collaboration opportunities within the UK academic arena, providing a detailed account of each opportunity according to ranking.

Garousi et al. (2016) provide a systematic review of industry-academia collaborations in the software engineering sector to identify the challenges and potential pitfalls of such collaborations such that future collaborators may remain aware of them. They also provide an inventory of best practices for collaboration in the sector. The authors provide a detailed description of the paper selection and review process. They provide four classifications of the papers in their review comprising of the knowledge area that they address, the contribution type, the research type and the scale of the review. Papers are also reviewed for collaboration models, challenges encountered and best practice advice. A comprehensive list of categorised challenges of industry-academia collaboration is supplied along with a complete list of best practices.

Mascarenhas et al. analyse co-cited references of university-industry collaboration to visualise clusters of topics they form (Mascarenhas et al., 2018). The analysis is performed using VOSviewer software (Van Eck and Waltman, 2009) which constructs bibliometric maps. Using this technique, categorisation of papers is performed automatically into clusters. Four clusters are identified: absorption capacity, knowledge and competitiveness of collaborations, impact of knowledge spillovers on collaborations, strategic alliances for industry innovation and university-industry cooperation. The top cited papers in each category are highlighted. They are also able to identify areas of university-industry

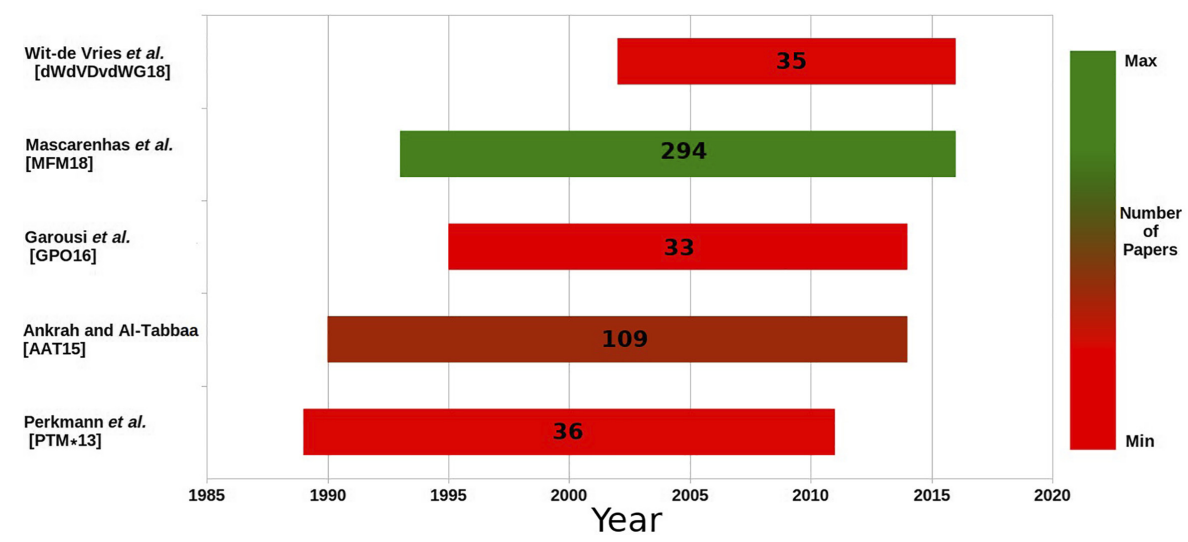

Industry engagement ladder
Figure 2.

A visualisation of the citation distribution for university-industry collaboration surveys. The number of papers each review surveys are indicated on the bars and indicated by the colour map. The year axis indicates the timespan of the references. See Section 2 on related work 

JIUC
2,3

collaboration that require more research, such as the monetary and social effects of these collaborations.

De Wit-de Vries et al. review 35 papers, focussing on the topic of knowledge transfer in industry-university partnerships (De Wit-de Vries et al., 2018). They identify barriers and facilitators for knowledge transfer between university and industry partners. Three themes of knowledge transfer barriers are identified which form the basis of their classification. These themes are cognitive difference, institutional differences and social capital. Wit-de Vries et al. provide a future research agenda following their work. This was compiled from inconsistencies found during their review, for example, the use of the term cultural difference can be ambiguous.

Roberts et al. have explored the motives for collaboration from both the industrial and academic side and how they do not always align (Roberts et al., 2018b). They provide recommendations for both industrial and academic partners to ensure a successful collaboration.

A book by Shneiderman (2016) articulates the need for research to be more focussed on applied problems and to combine research across science, engineering and design disciplines. A section on industry-university collaboration highlights its benefits. Firstly, industry has real-world problems that university researchers can address as opposed to theoretical problems. Secondly, industry has data that universities would find difficult to obtain themselves. And finally, universities have several young researchers, whereas industries have resources for them to use.

Shneiderman does caution against some of the pitfalls of collaboration, however. He notes that it can take time for each party to understand the internal processes of one another which could cause barriers. He also notes that often universities and businesses have different policies with regard to confidentiality, with businesses wanting to keep a competitive advantage over their competitors and universities looking to publish results.

Our work differs from previous work in that it offers concrete examples, based on practice and experience, in the form of an investment and risk ladder. These examples can be used by any department interested in collaboration with industry. We used each of these in the Department of Computer Science at Swansea University. We also find very similar opportunities at the University of Nottingham.

\section{The Industry Engagement Ladder}

There are several options for collaboration. They are presented as list starting with the smallest and lowest risk investment and then generally increasing as the ladder ascends. Figure 1 shows the Industry Engagement Ladder. An indication also outlines the type of activity each rung represents, being a teaching activity or a research activity. For most, it may make sense to start at the bottom of the ladder and work your way up as the collaborative relationship develops. Here we outline the details of each rung on the Industry Engagement Ladder. Table 1 provides a summary of the engagement opportunities and the associated investments.

\subsection{Guest lecture}

Guest lectures are a great way to recruit and advertise to students. For example, anyone may give a guest lecture in a software engineering module in a computer science programme at a British university, and we are always looking for industry sponsors for our group prizes. Past industrial sponsors include CA Technologies and Grid-Tools Ltd.

Most computer science departments have many seminar series covering different topics. An example of which is the Visible Lunch (Laramee, 2019b). The Visible Lunch event aims to 


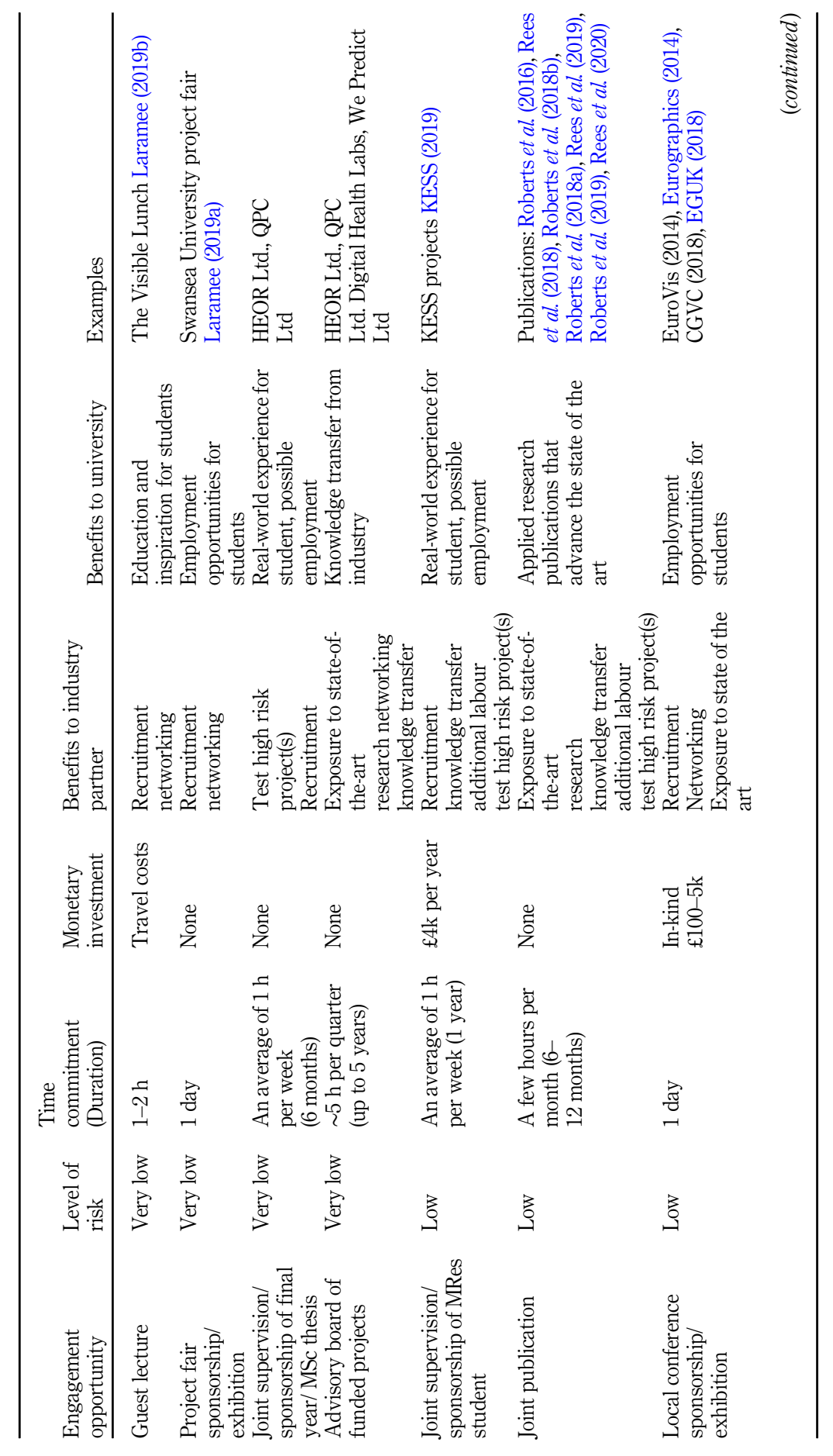

Industry engagement ladder

129

Table 1.

A table summarising the engagement possibilities, the associated risks and commitments required and our collaboration examples 


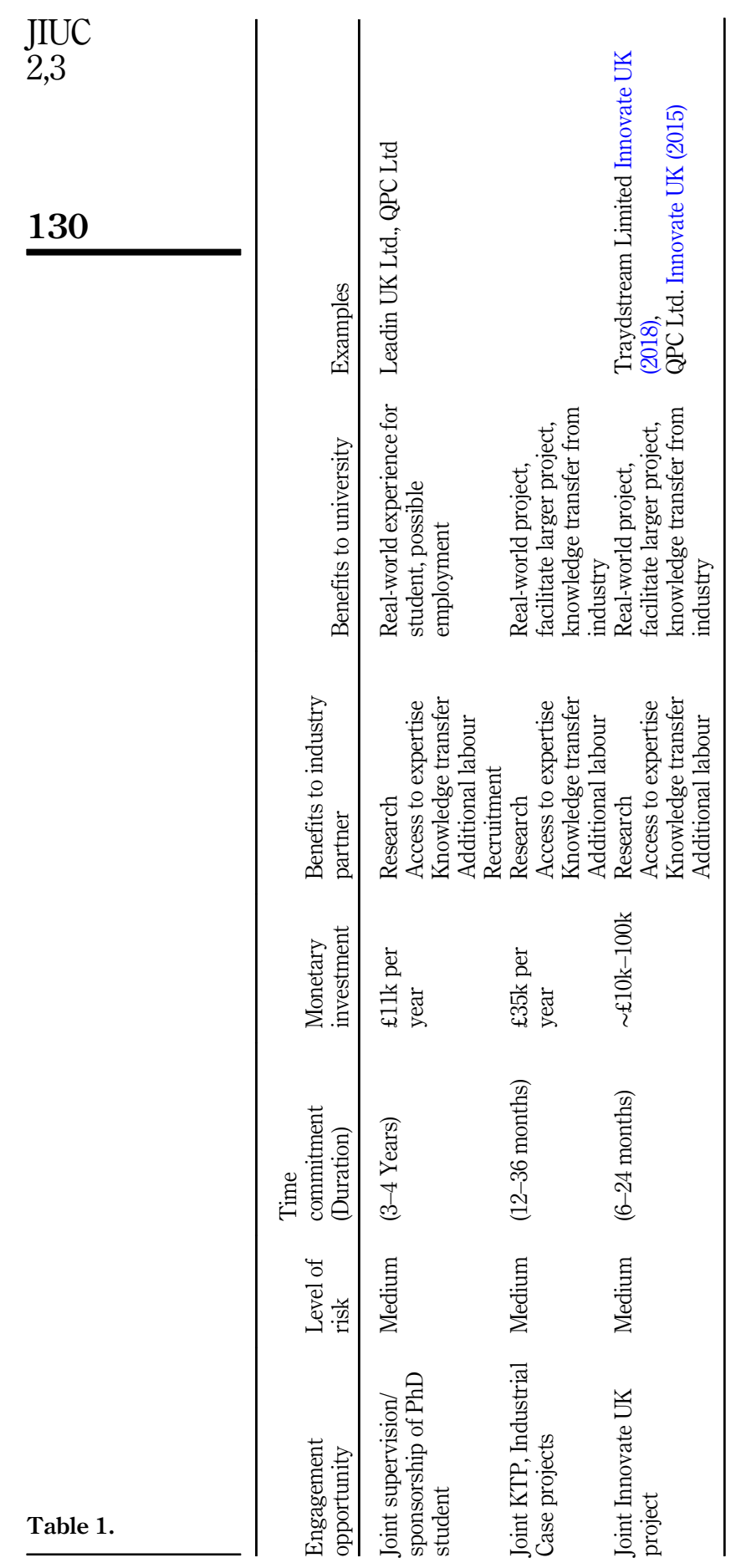


bring together researchers at university (and surroundings) with a common interest in visual computing. This event encourages informal discussion, open exchange and personal interaction in order to foster both research directions in visual computing and a sense of local community. Anyone may give a guest lecture at our regular Visible Lunch event. This can take place at any time of the year. Past guest lectures have been presented by the Renishaw Group, City and County of Swansea and General Dynamics.

We also invite industry collaborators to give invited talks at our Annual Undergraduate Colloquium at Gregynog (Laramee, 2014). Since 1985, students and staff of the Computer Science Department at Swansea attend an annual 2-3 day Undergraduate Computer Science Colloquium at Gregynog, the conference centre near Newtown, Wales. The aim of the colloquium is to provide:

(1) An overview of Computer Science, its research and applications, its history and future developments

(2) An opportunity for every student to give a presentation about their project

(3) An open discussion between staff and students on education in Computer Science

(4) A reflection on career prospects for Computer Science students

(5) Informal conversation between staff and students.

As a part of the colloquium, every student presents their project work and invited speakers from both academia and industry present on various aspects of Computer Science, including research, commercial and industrial themes. In the past, the colloquium has hosted speakers from a variety of industries including BT, Fujitsu, IBM and DVLA, as well as presentations from other universities and other departments within Swansea University.

This option represents the lowest risk and investment for collaboration, requiring only a minimal investment of time and perhaps some minimal travel expenses.

\subsection{Project fair sponsorship, exhibition}

Some universities showcase undergraduate projects to a wider audience of industrial partners and interested parties in an exhibition. At Swansea University, final-year computer science students dedicate two semesters to their final year project as part of their degree qualification. Since 2008, these students present the results of their project to the departmental public as well as to local IT industry. The aim of the fair is to provide students with a professional environment where they:

(1) Present and defend their final-year projects

(2) See how their own project fits into the context of the entire year's results.

(3) Network professionally with IT companies.

During the fair, students engage by their exhibition space in discussions with visitors from the entire local area community. This is a great opportunity to come and meet the latest group of graduates as well as to network with visitors from local academia and industry. Industry-sponsored prizes are also awarded on the day. In the past, the fair has been sponsored by companies such as ERS Insurance Group and Health Economics and Outcomes Research (HEOR) Ltd. Plate 1 shows an image of a previous project fair. Similar to the guest lecture, this collaboration requires minimal resources and represents an extremely low investment. 


\section{JIUC 2,3}

132

\subsection{Joint supervision/sponsorship of final year/MSc thesis}

Every final-year undergraduate student at most British universities works on a project for two semesters. They can choose to work with industry on their project. Students choose their project around April-May each year from a project selection brochure we distribute annually. We can include a collaborative project in the brochure. Laramee provides a sample list of data visualisation projects (Laramee, 2018). This can serve as a low-risk, low-investment starting point for collaboration, enabling pilot testing of an idea. Examples of companies collaborating with us in this way are Health Economics and Outcomes Research (HEOR) Ltd. and QPC Ltd. There are some drawbacks, however. Students may not choose an industry project. Also, a student that does choose such a project may not succeed at it.

Every master's student chooses a project for their thesis in the December-January time frame. A collaborative project may be included in their project selection brochure. This option is very similar to the third-year project option although the students are more mature. One advantage of this option again is that it is very low risk and low investment and can serve as a starting point for collaboration. However, the same disadvantages as third-year projects hold, a student may not choose an industry project. Also, only the best student projects provide a proof of concept to industry.

\subsection{Advisory board of a funded project}

Academics are often applying for grants to fund research projects from government bodies such as the EPSRC (2019a, b). These funded projects are often supported by industrial partners to provide industrial expertise and validation of projects. For the industrial partner, this gives insight into the latest state of the art in research or provides a proof of concept. Companies that have collaborated with us in this way in the past include QPC Ltd., Digital Health Labs, HEOR Ltd. and We Predict Ltd.

This is another very low-risk collaboration, again requiring only time as an input. However, funded projects may run over a number of years, thus it represents a slightly higher risk than collaboration opportunities on lower rungs of the ladder.

\subsection{Joint supervision/sponsorship of MRes student}

Both Master of Research (MRes) and Master of Science by Research (MbyRes) degrees are research-oriented master's degrees. Students dedicate significantly more time and effort to their thesis than in the cases of a third-year project or a taught (standard MSc) master's degree. This enables the pilot testing of a more substantial project. Funding opportunities can be used to attract high-quality students. The Knowledge Economy Skills Scholarships
Plate 1.

An image from the annual undergraduate student project fair. See Section 3.2

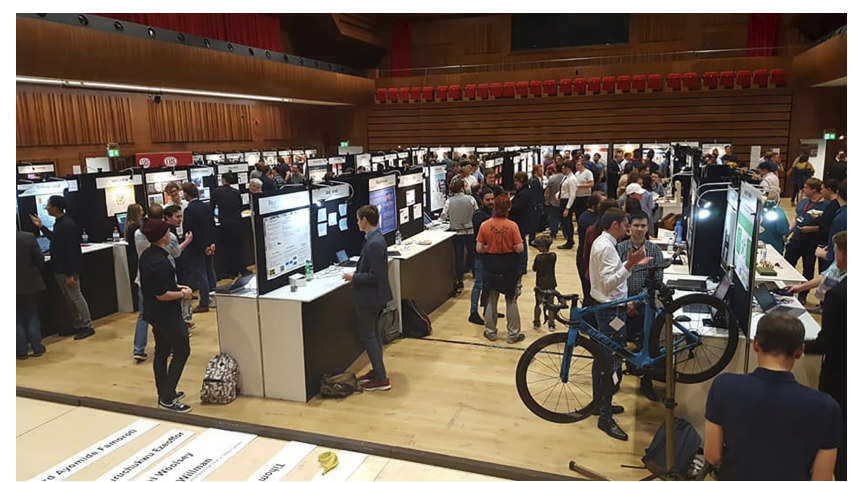


(KESS 2) programme funds high-quality MRes degrees (KESS, 2019) in Wales. KESS 2 links companies and organisations with academic expertise to undertake research projects that meet the needs of an active business or its sector. Companies that we have collaborated with on KESS 2 projects include Grid-Tools Ltd. (now CA Technologies), We Predict Ltd., Leadin UK Ltd. (now Gofore UK Ltd.) and QPC Ltd. KESS 2 is a collaborative project supported by European Social Funds (ESF) through the Welsh Government involving all universities in Wales.

In this case the academic leads the application process. We have had a number of successful KESS-funded MRes and $\mathrm{PhD}$ degree students in conjunction with industry. Application deadlines are usually between January and June each year. These degrees usually start in October or January each year. The industry contribution to KESS degrees is about £4K GBP per annum. The chances of success are much higher in this case than for BSc or MSc degree projects. These degrees tend to attract high-quality students that dedicate a significant amount of time to their industry projects.

We rate this collaboration as low compared to very low with the opportunities on lower rungs of the Engagement Ladder. The reason for this is that some financial investment is required, although this is relatively small. Most of the investment comes from the academic side.

\subsection{Joint publications}

Collaboration on joint publications is often welcome. This may be to provide industrial domain expert validation for a particular project. As an example, we cite joint publications between us and QPC Ltd., a call centre infrastructure provider (Rees et al., 2018, 2019, 2020; Roberts et al., 2016, 2018a, b, 2019).

These publications present novel, feature-rich and interactive application to visualise various aspects of up to 5,000,000 calls. For this collaboration, QPC Ltd. provided a data set, guidance and domain expert feedback on the product developed. Another collaborating company is We Predict Ltd., who also provided a data set and guidance towards a joint publication (Nicholas et al., 2014).

This is another low-risk collaboration, with the risk dependent on the specific agreement of the collaboration, which may include a small financial contribution from the industry partner towards the project costs.

\subsection{Local conference sponsorship, exhibition}

Universities often host conferences to showcase their latest research findings. These conferences can vary in size and exposure, ranging from small to the international level. These conferences offer sponsorship opportunities for industry partners. In return, industry partners are able to use these conferences for exposure to a larger audience through an exhibition or by giving a presentation, providing advertising and recruitment opportunities.

The frequency of these conferences can be sporadic and for a variety of different computer science subjects. Examples of previously hosted conferences at Swansea University are EuroVis 2014 (Eurographics, 2014) sponsored by Winton, Tableau and NVIDIA, amongst others (see Plate 2), and CGVC 2018 (EGUK, 2018) sponsored by the Computers Journal.

The investment risk of a conference sponsorship or exhibition is low, requiring only a relatively small financial contribution. This contribution is dependent on a number of factors such as the level of involvement and the nature and profile of the conference or exhibition.

\subsection{Joint supervision/sponsorship of PhD student}

$\mathrm{PhD}$ candidates may choose to work with industry on their research degrees. There is also the possibility to sponsor a $\mathrm{PhD}$ student through a match-funded
Industry engagement ladder 


\section{JIUC 2,3}

\section{4}

Plate 2.

An image from the 2014 EuroVis conference hosted at Swansea University. See Section 3.7

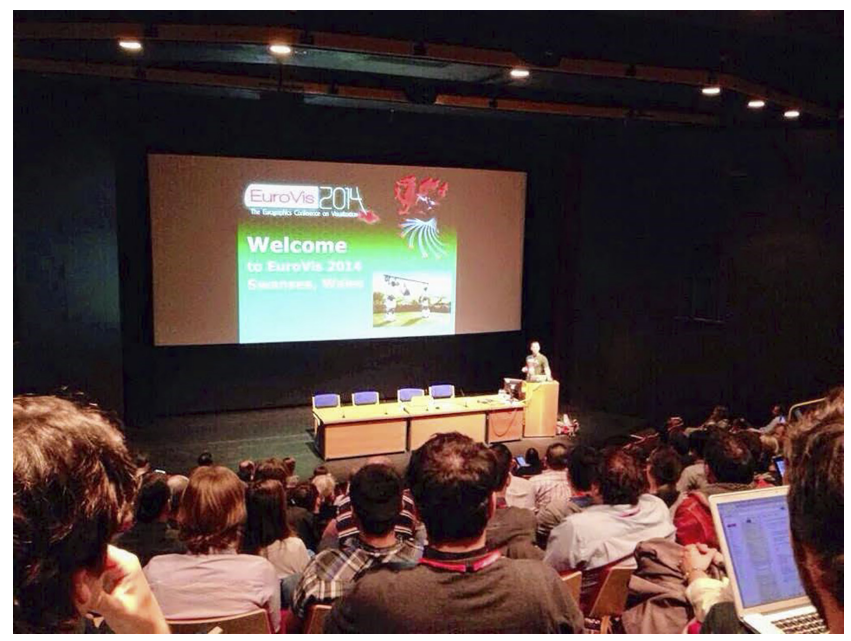

(50/50\%) PhD Studentship in conjunction with the College of Science at Swansea University. This programme is normally not advertised publicly. The deadline for match-funding $\mathrm{PhD}$ studentship applications is usually once each year. The cost is around $£ 11 \mathrm{~K} \mathrm{GBP} /$ year for three years for industry partners. $\mathrm{PhD}$ students can start four times per year at the beginning of each quarter (1 Jan, 1 Apr, 1 July, 1 Oct). There are many benefits to sponsoring a $\mathrm{PhD}$ student with an industry project. Appendix describes some more details and benefits.

KESS 2 (KESS, 2019), described in Section 3.5, also has part-funded PhD Studentships with an emphasis on industrial collaboration. We have successfully collaborated on a number of KESS PhD studentships. Companies that have jointly supervised a $\mathrm{PhD}$ student with KESS projects include Grid-Tools Ltd., Leadin UK Ltd. and QPC Ltd.

\subsection{Joint KTP, industrial case project}

Knowledge Transfer Partnerships (KTP) are very popular for collaboration. The KTP scheme links a UK-based business with an academic institution and provides a graduate research assistant (RA) (Innovate UK, 2019). The RA normally resides at the industry partner for most of the time, with schemes lasting 12-36 months. This provides the business with academic expertise that they otherwise might not have access to for development of new prototypes and products. The application process is led by the academic. The risk associated with this collaboration is low with small and medium-sized enterprises contributing around $£ 35,000$ per year, about one-third of the project costs.

Industrial Cooperative Awards in Science \& Technology (case) are specifically for $\mathrm{PhD}$ studentships in conjunction with industry (EPSRC, 2019c). Students are required to spend a minimum of three months at the partner business, enabling an opportunity to explore novel research. This studentship is funded by the ESPRC (EPSRC, 2019b) and represents a medium-risk collaboration.

\subsection{Joint Innovate UK project}

Innovate UK is part of a public body funded by the UK government to nurture innovation and create successful products from joint ideas (UK Research and Innovation, 2019). Innovate UK 
projects can be used to hire a dedicated research assistant (RA) for varying lengths of time, typically from 6 to 24 months. The UK government typically covers about $70 \%$ of the company's costs on the project (and 100\% of the academic's costs).

Swansea University has positive experiences and successes with Innovate UK programmes and has some previous applications we are happy to share to get an idea of what an application is like (Innovate UK, 2015) (See Plate 3. The application process is led by the industry partner; however, we can certainly help an industry partner write an application. Examples of successful Innovate UK project collaborators include Traydstream Limited (Innovate UK, 2018) and QPC Ltd. (Innovate UK, 2015).

This collaboration requires the most investment in terms of time and financial resource and therefore has the highest risk of all the collaborations outlined in this paper. However, an Innovate UK project also can provide the biggest benefit, with the resources available to produce a high-quality prototype, product, research or study.

\section{Academic engagement ladder}

The Industry Engagement Ladder can be adapted to create a similar engagement structure for cross-department collaboration within the university or across universities. This is illustrated in Figure 3.

Many of the engagement rungs are similar to that of the Industry Engagement Ladder, and so the engagements follow a similar protocol but with the academic partner instead of the industry partner. The primary difference between the academic and industry engagement ladders is the absence of opportunities for conference sponsorship or exhibitions due to differing disciplines. Governmental initiatives for fostering industry-university collaboration are also not available without an additional industrial partner.

\section{Future work and discussion}

Collaboration enables exchange of ideas and resources to the benefit of all collaborating partners. However, not all collaborations end in success. By providing an engagement ladder, opportunities for lower-risk collaborations are indicated, enabling collaboration where high exposure is not an option. Lower-risk collaboration also enables testing a relationship, before climbing the ladder to a higher-risk exposure.

The landscape of available grants is not fixed, successive governments may have different policies on research, therefore not all funding opportunities will be available in the future and

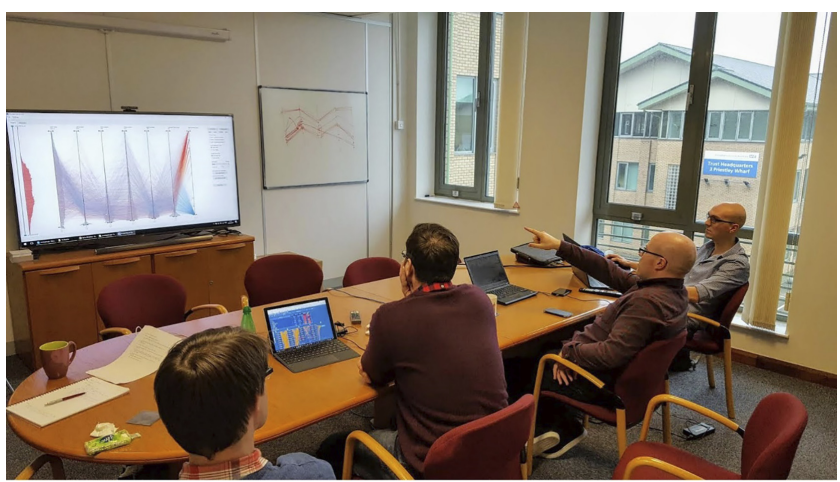

Industry engagement ladder 


\section{JIUC 2,3}

\section{6}

Figure 3.

The Interdisciplinary Academic Engagement Ladder, outlining what collaboration opportunities exist for university departments for interdisciplinary collusion. The higher up the ladder, the higher the investment and therefore risk. Greater investment usually corresponds to a longer relationship. The Interdisciplinary Academic Engagement Ladder is very similar to the Industry Engagement Ladder with minor variations due to available funding

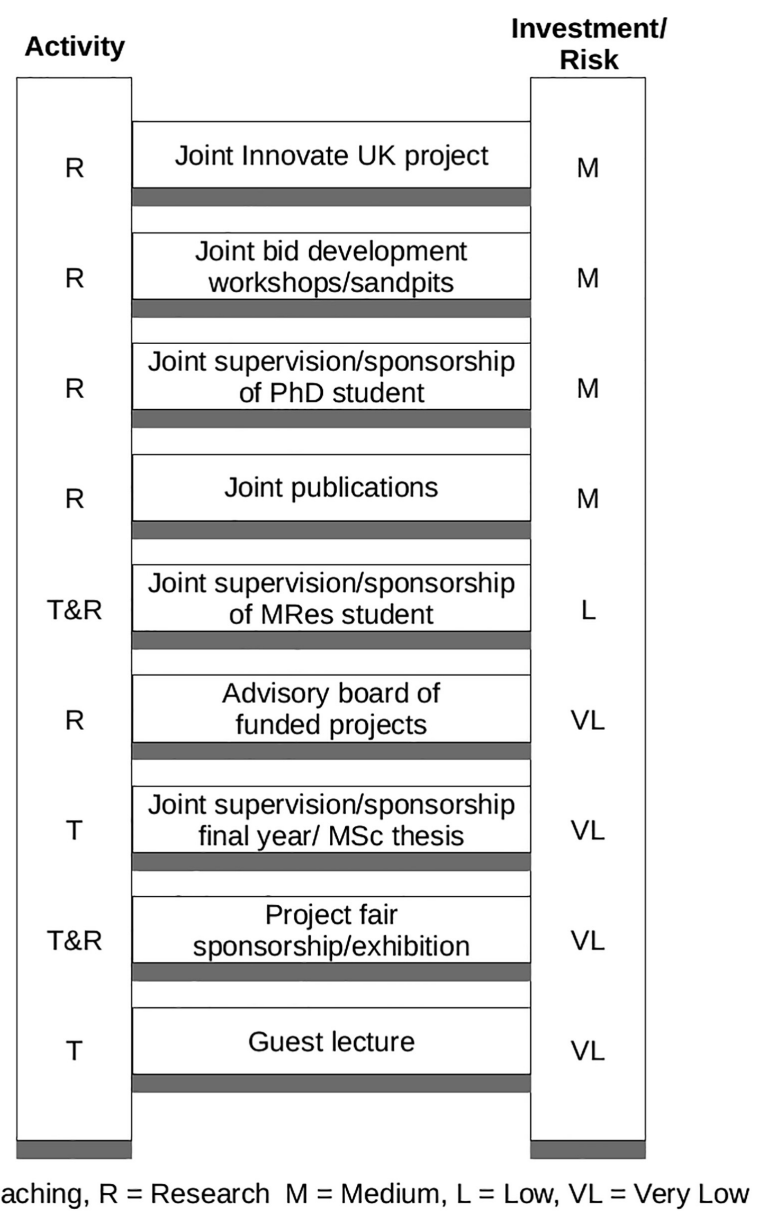

other opportunities may also be introduced. To keep this document up to date with latest developments is future work.

\section{Conclusion}

In this paper we outline the available opportunities for collaboration between industry and universities, drawn from our own experiences. We present this information in the form of a ladder with a ladder scale of increasing risk and reward. This manuscript offers an ideal starting point for industry-university collaboration.

\section{References}

Ankrah, S. and Al-Tabbaa, O. (2015), "Universities-industry collaboration: a systematic review", Scandinavian Journal of Management, Vol. 31 No. 3, pp. 387-408.

Bonaccorsi, A. and Piccaluga, A. (1994), "A theoretical framework for the evaluation of universityindustry relationships”, R\&D Management, Vol. 24 No. 3, pp. 229-247. 
De Wit-de Vries, E., Dolfsma, W.A., van der Windt, H.J. and Gerkema, M.P. (2018), "Knowledge transfer in university-industry research partnerships: a review", The Journal of Technology Transfer, Vol. 44 No. 4, pp. 1236-1255.

EGUK (2018), CGVC 2018, available at: https://cgvc.org.uk (accessed 3 February 2020).

EPSRC (2019a), EPSRC Grant - Bringing Healthcare Data to Life, available at: https://gtr.ukri.org/ projects? $\mathrm{ref}=\mathrm{EP} \% 5 \mathrm{C} \% 2 \mathrm{FS} 010238 \% 5 \mathrm{C} \% 2 \mathrm{~F} 1$ (accessed 3 February 2020).

EPSRC (2019b), ESPRC, available at: https://epsrc.ukri. org (accessed 3 February 2020).

EPSRC (2019c), "Industrial CASE”, available at: https://epsrc.ukri.org/skills/students/coll/icase/intro (accessed 3 February 2020).

Eurographics (2014), EuroVis 2014, available at: http: //eurovis.swansea.ac.uk (accessed 3 February 2020).

Garousi, V., Petersen, K. and Ozkan, B. (2016), "Challenges and best practices in industry-academia collaborations in software engineering: a systematic literature review", Information and Software Technology, Vol. 79, pp. 106-127.

Innovate, U.K. (2015), "Innovate UK grant - visualising customer journeys through the call centre landscape", available at: https:/gtr. ukri.org/projects?ref=101939 (accessed 3 February 2020).

Innovate, U.K. (2018), Innovate UK Grant - Trade Finance Fraud Detection Project in Dual Use Goods with Machine Learning and Visual Analytics, available at: https://gtr.ukri.org/projects? ref $=104413$ (accessed 3 February 2020).

Innovate, U.K. (2019), Knowledge Transfer Partnership, available at: https://www.gov.uk/guidance/ knowledge-transfer-partnershipswhat-they-are-and-how-to-apply (accessed 3 February 2020).

KESS (2019), KESS 2 Knowledge Economy Skills Scholarships, available at: http://kess2.ac.uk/ (accessed 3 February 2020).

Laramee, R.S. (2014), The Annual Computer Science Undergraduate Colloquium at Gregynog, available at: http://cs.swan. ac.uk/ csbob/teaching/gregynog (accessed 3 February 2020).

Laramee, R.S. (2017), Academic - Industry Gaps: Panel at the Uncertainty Quantification \& Management for Industry Event; YouTube Video, available at: https://www.youtube.com/ watch? $\mathrm{v}=$ fCYhTX7Imc8 (accessed 3 February 2020).

Laramee, R.S. (2018), Projects in Data Visualization, available at: http://cs.swan.ac.uk/ csbob/teaching/ cs354-projectSpec/laramee18projectBrochure.pdf (accessed 3 February 2020).

Laramee, R.S. (2019a), The Annual Computer Science Project Demonstration Fair, available at: http:// cs.swan.ac.uk/ csbob/teaching/ projectFair/ (accessed 3 February 2020).

Laramee, R.S. (2019b), The Visible Lunch, available at: http://cs.swan.ac.uk/ csbob/visibleLunch/ (accessed 3 February 2020).

Mascarenhas, C., Ferreira, J.J. and Marques, C. (2018), "University- industry cooperation: a systematic literature review and research agenda", Science and Public Policy, Vol. 45 No. 5, pp. 708-718.

Nicholas, M., Archambault, D. and Laramee, R.S. (2014), "Interactive visualisation of automotive warranty data using novel extensions of chord diagrams", Proceedings of EuroVis Short Papers 2014, The Eurographics Association, pp. 115-119.

Perkmann, M., Tartari, V., McKelvey, M., Autio, E., Broström, A., D’Este, P., Fini, R., Geuna, A., Grimaldi, R., Hughes, A. and Krabel, S. (2013), "Academic engagement and commercialisation: a review of the literature on university-industry relations", Research Policy, Vol. 42 No. 2, pp. $423-442$.

Rees, D., Roberts, R.C., Laramee, R.S., Brookes, P., D’Cruze, T. and Smith, G.A. (2018), “GPU-assisted scatterplots for millions of call events", Computer Graphics and Visual Computing (CGVC), pp. 71-79, The Eurographics Association.

Rees, D., Roberts, R.C., Laramee, R.S., Brookes, P., D'Cruze, T. and Smith, G.A. (2019), "Feature-rich, GPU-assisted scatterplots for millions of call events", Computers, Vol. 8 No. 1, pp. 1-22.

Industry engagement ladder . 


\section{JIUC 2,3}

Rees, D., Laramee, R.S., Brookes, P., D’Cruze, T., Smith, G.A. and Miah, A. (2020), "AgentVis: visual analysis of agent behavior with hierarchical glyphs", IEEE Transactions on Visualization and Computer Graphics, available at: https://ieeexplore.ieee.org/document/9067088.

Roberts, R.C., Tong, C., Laramee, R.S., Smith, G.A., Brookes, P. and D’Cruze, T. (2016), "Interactive analytical treemaps for visualisation of call centre data", The Eurographics Association, Smart Tools and Apps for Graphics, pp. 109-117.

Roberts, R.C., Rees, D., Laramee, R.S., Brookes, P. and Smith, G.A. (2018a), "RiverState: a visual metaphor representing millions of time-oriented state transitions", Computer Graphics and Visual Computing (CGVC), pp. 81-89, The Eurographics Association.

Roberts, R.C., Laramee, R.S., Brookes, P., Smith, G.A., D'Cruze, T. and Roach, M.J. (2018b), "A tale of two visions-exploring the dichotomy of interest between academia and industry in visualisation”, VISIGRAPP (IVAPP), Vol. 3, pp. 319-326.

Roberts, R.C., Laramee, R.S., Smith, G.A., Brookes, P. and D'Cruze, T. (2019), "Smart brushing for parallel coordinates", IEEE Transactions on Visualization and Computer Graphics, Vol. 25 No. 3, pp. 1575-1590.

Shneiderman, B. (2016), The New ABCs of Research: Achieving Breakthrough Collaborations, Oxford University Press, Oxford.

Shneiderman, B. (2018), "Twin-win model: a human-centered approach to research success", Proceedings of the National Academy of Sciences, Vol. 115 No. 50, pp. 12590-12594.

GOV.UK (2019), Research and Development (R\&D) Tax Reliefs, available at: https:/www.gov.uk/ guidance/corporation-taxresearch-and-development-rd-relief (accessed 3 February 2020).

UK Research and Innovation (2019), Innovate UK, available at: https:/www.gov.uk/government/ organisations/innovate-uk (accessed 3 February 2020).

Van Eck, N.J. and Waltman, L. (2009), "Software survey: VOSviewer, a computer program for bibliometric mapping", Scientometrics, Vol. 84 No. 2, pp. 523-538.

\section{Appendix}

Business case for sponsoring a $\mathrm{PhD}$ student in data visualisation and visual analytics

Britain's universities play an essential role in shaping the UK's future and delivering prosperity, from educating future business leaders to developing innovations crucial to the nation's progress. The HE sector contributes more than $£ 73 \mathrm{bn}$ a year to the UK economy. British universities have a growing interest in outward-facing collaboration including industry in order to maximise relevance and impact.

$\mathrm{PhD}$ candidates may choose to work with industry on their research degrees. Some British universities offer the possibility of sponsoring a $\mathrm{PhD}$ student through a match-funded $(50 / 50 \%) \mathrm{PhD}$ Studentship in conjunction with the College of Science. This programme is generally not advertised publicly. The deadline for match-funding $\mathrm{PhD}$ studentship applications is usually at the beginning of February each year for $\mathrm{PhD}$ candidates with an October start. At the time of writing, the cost of sponsoring a PhD student is around 11.5K GPB per year for three years for partners. (The total cost of a $\mathrm{PhD}$ candidate is around $£ 70 \mathrm{~K} \mathrm{GBP}$.) $\mathrm{PhD}$ students can typically start four times per year at the beginning of each quarter (1 Jan, 1 Apr, 1 July, 1 Oct). Here are some great reasons to sponsor a PhD candidate:

(1) Innovation: One key to staying competitive in any market is innovation. Research is a key element to drive innovation. Academic leaders invest several thousand pounds every year in maintaining their knowledge of the most recent developments in the field on a global level.

(2) Expertise: Laramee, the $\mathrm{PhD}$ candidate's supervisor, has been studying and specialising in data visualisation and research since 1999. This kind of expertise is very rare in the UK. There are only a handful of academics specialising in visualisation across the entire UK. As an academic, he is also interested in maintaining a competitive edge in a global research field. 
(3) Inexpensive labour: Hiring a $\mathrm{PhD}$ candidate is much less expensive than an employee. This is a great opportunity to test out high-risk proof-of-concept prototype software. It is also a great opportunity to test out a prospective employee.

(4) 2 for the price of 1: Although you may choose to sponsor one $\mathrm{PhD}$ student, you are really hiring two people, the candidate and the $\mathrm{PhD}$ supervisor. The candidate's $\mathrm{PhD}$ supervisor works very closely with the $\mathrm{PhD}$ candidate on training, guidance, software development and innovation.

(5) Tax deductions for research: Research and development (R\&D) tax credits are a valuable government tax relief that rewards UK companies for investing in innovation. Companies that spend money developing new products, processes or services, or enhancing existing ones, are eligible for a cash payment and/or Corporation Tax reduction. R\&D reliefs support companies that work on innovative projects in science and technology. It can be claimed by companies that incorporate research in order to advance in their market. It can even be claimed on unsuccessful projects. More information on R\&D tax reliefs can be found on the Government website (GOV.UK, 2019). Some companies may even generate a net profit from such collaboration.

\section{Corresponding author}

Dylan Rees can be contacted at: 849119@swansea.ac.uk

For instructions on how to order reprints of this article, please visit our website: 